\title{
Effects of elastic band orthosis (aider) on balance and gait in chronic stroke patients
}

\author{
Noha Daher ${ }^{a}$, Seungjun Lee ${ }^{b}$, You Jin Yang ${ }^{b}$ \\ ${ }^{a}$ Department of Epidemiology, Biostatistics, and Population Medicine, Loma Linda University, CA, USA \\ ${ }^{B}$ Department of Rehabilitation Medicine, Wonju Medical Center, Wonju, Republic of Korea
}

Objective: The objective of this study was to investigate the feasibility and effects of balance training using a newly developed elastic band orthosis (aider) for improvement of mobility and balance in chronic stroke patients.

Design: Cross-sectional study.

Methods: Ten patients with chronic hemiplegia participated in this study. There were six males and four females; two patients had right hemiplegia and eight had left hemiplegia. This study investigated the effect of the elastic band orthosis on balance and gait ability compared with bare foot condition. Gait parameters were measured using the opto-gait system for analysis of the spatial and temporal parameters of walking in stroke patients. In addition, balance ability in stroke patients was evaluated using the Timed Up and Go (TUG) and Berg Balance Scale (BBS).

Results: This study investigated the effect of the elastic band orthosis on balance compared with bare foot condition. The TUG and BBS showed significant improvement with use of the elastic band orthosis $(p<0.05)$. Use of the Elastic band orthosis resulted in significantly improved velocity, cadence, less-affected step length, less-affected stride length, and less-affected single limb support in stroke patients $(p<0.05)$.

Conclusions: We demonstrated a significant improvement in dynamic balance and gait ability in chronic stroke patients using the elastic band orthosis. This orthosis may aid in prevention of spastic foot drop, leading to improvement of walking ability.

Key Words: Ankle-foot orthosis, Balance, Gait, Stroke

\section{Introduction}

The ability to walk independently is a life enriching activity and the most efficient way of getting from one place to another in the course of our daily lives [1]. Stroke often results in dysfunction of one side of the body termed hemiplegia [2]. Compared with able bodied persons, the gait of persons with hemiplegia is less metabolically efficient and leads to increased falls $[3,4]$. Limitation of the ability to walk is one reason for restricted mobility locomotor disability after stroke [5].

Problems with poor balance, instability in stance, hypertonicity, inappropriate and involuntary posturing of the foot and ankle, and recurvatum and instability at the knee have led to the recommendation that orthoses be incorporated in the lower limb management of patients after stroke [6]. For example, approximately $20 \%$ of stroke patients suffer from spastic foot-drop, which is an inability to dorsiflex the foot and can cause deficiencies in toe clearance during gait $[7,8]$.

Ankle-foot orthosis (AFO) is currently the most widely used orthoses in the United States, accounting for $26 \%$ of clinical practice by certified orthotists [9]. AFOs are generally used to assist hemiplegic patients in regaining walking ability [10], preventing foot-drop and the occurrence of toe clearance problems, promoting mediolateral ankle stability during standing, and promoting heel strike [11].

Received: 2 October, 2013 Revised: 9 December, 2013 Accepted: 11 December, 2013

Corresponding author: You Jin Yang

Department of Rehabilitation Medicine, Wonju Medical Center, 387 Seowon-daero, Wonju 220-709, Republic of Korea

Tel: 82-33-760-4500 Fax: 82-33-761-5121 E-mail: yyj0622@nate.com

(c) This is an Open-Access article distributed under the terms of the Creative Commons Attribution Non-Commercial License (http://creativecommons.org/licens es/by-nc/3.0) which permits unrestricted non-commercial use, distribution, and reproduction in any medium, provided the original work is properly cited.

Copyright $@ 2013$ Korean Academy of Physical Therapy Rehabilitation Science 
Several researchers, however, insist that there are some problems with AFOs, such as disuse of the ankle dorsiflexor when patients undergo gait training with AFOs for a long period of time, as well as a lack of evidence for increased muscle activation [12]. Thus, it remains uncertain whether AFOs should be considered for improvement of functional recovery in stroke patients as they may replace muscle activity according to the degree of assistance. In addition, some researchers have indicated that immobilization of the ankle with AFOs would induce muscle disuse [13]. Articulated AFOs with plantar flexion stops are frequently provided for patients with hemiplegia [12].

Therefore, development of a new assistive device for stroke patients that is lighter, portable, and better customized, with a low cost is needed.

In this study, we compared the effect of elastic band orthosis and bare foot condition on balance and gait patterns in stroke patients.

\section{Methods}

\section{Subjects}

Ten participants diagnosed with hemiplegia were recruited from W Medical Center in Wonju, Korea. There were six males and four females; two patients had right hemiplegia and eight had left hemiplegia (Table 1).

Inclusion criteria were (a) a diagnosis of hemiplegia due to hemorrhagic or ischemic stroke, (b) more than six months post-stroke, (c) the ability to follow simple instructions, (d) the ability to walk independently or with an assistive device, and (e) no orthopedic problems involving the lower extremities that would affect gait.

Exclusion criteria were (a) a stroke involving more than one hemisphere, (b) more than two strokes, and (c) premorbid or other orthopedic problems that would impede gait patterns. Informed consent was provided by the subjects prior to the start of the study. The study was approved by the Sahmyook University Ethics Committee.

Table 1. General characteristics of the subjects

$(\mathrm{N}=10)$

\begin{tabular}{lc}
\hline \multicolumn{1}{c}{ Characteristic } & Mean (SD) \\
\hline Age (yr) $^{*}{ }^{*}$ (male:female) & $56.8(13.51)$ \\
Gender $^{*}$ (right:left) & $6: 4$ \\
Affected side of stroke $^{*}$ & $7: 3$ \\
Stroke onset (mo) & $42.30(17.11)$ \\
\hline
\end{tabular}

*Frequency.

\section{Procedures}

Before conduct of the tests, the investigators demonstrated walking on the Optogait system. The participants were asked to walk at a comfortable speed. Assistance was provided if the subjects required it for safety. Each test was performed over the course of five trials by each participants and a 2-min rest period was provided between tests. Participants performed the test initially with bare feet for 1-2 $\mathrm{m}$ to allow them to adapt to walking on it before they used the elastic band orthosis.

\section{Outcome measures}

\section{Timed Up and Go test}

The Timed Up and Go (TUG) is a time measured test that requires standing up, walking straight for $3 \mathrm{~m}$, turning, walking back to the chair, and sitting down. In this study, participants sat comfortably on a chair and did not use back support. They were timed for the TUG as soon as their buttocks lifted from the chair and as soon as their buttocks touched the seat. For turning, they moved toward the unaffected side. A time less than 10 seconds indicated functional independence, and a time more than 30 seconds indicated functional dependence. The time was recorded using a stopwatch. The intrarater reliability of the TUG was high in individuals with chronic stroke. One study reported an ICC of 0.95 (95\% confidence interval [CI], 0.84-0.99), and another study reported an ICC of 0.96 (95\% CI, 0.93-0.98) $[14,15]$.

\section{Berg Balance Scale}

The Berg Balance Scale (BBS) is a functional balance measurement consisting of 14 items. Each item is a 5-point ordinal scale ranging from 0 to 4 , with 0 indicating an inability to complete the task entirely and 4 indicating an ability to complete the task criterion. Scores can range from 0 to 56 . The higher the score, the better the postural control for individuals with stroke. Cronbach's $\alpha$ of the BBS ranged from 0.92 to 0.98 showing high internal consistency [16]. The inter-rater reliability had an ICC of 0.95 (95\% CI, 0.93-0.97), the intra-rater reliability was high (ICC $=0.97)$, and the test-retest reliability had an ICC of 0.98 . $[17,18]$.

\section{Optogait system}

The Optogait system used in this study consisted of five transmitting and five receiving bars, which were placed parallel to each other $(3 \times 0.5 \mathrm{~m})$ for collection of gait 
parameters. Each Optogait bar $(100 \times 8 \mathrm{~cm})$ contained 96 light-emitting or light-receiving diodes (approximately one every centimeter), which are located $3 \mathrm{~mm}$ above the floor level. The first Optogait bar was placed approximately 40 $\mathrm{cm}$ from the starting point so that the very first step was recorded by the system.

Participants were consistently asked to start walking using the right foot (right step). Data were sampled at $1,000 \mathrm{~Hz}$ and processed into $1 \mathrm{D}$ footfall patterns using dedicated software (Optojump Next, Version 1.3.20.0; Microgate, Bolzano, Italy) [18].

\section{Elastic band orthosis (aider)}

Architecture of the elastic band orthosis consists of opened toe socks and two straps (Figure 1). Sock length is toe to mid-metatarsal area and the heel is opened. Straps are attached on both sides of the socks. A long strap is attached on the medial side this strap goes across the top of the lateral malleolus and is turned around to the opposite side and then fastened with Velcro. The short strap is attached on the lateral side of the socks; this strap goes across top of the foot and then the strap is stuck to the Velcro (Figure 2).

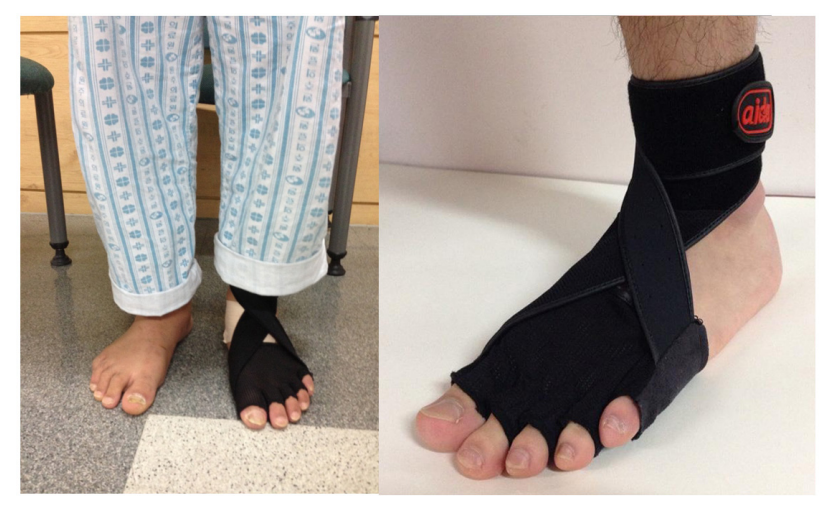

Figure 1. Anterior and side view of the elastic band orthosis in a stroke patient.

\section{Data analysis}

In this study, data was analysed using IBM SPSS Statistics version 22.0 for Windows (IBM Co., Armonk, NY, USA). Descriptive statistics were used to summarize the general characteristic of participants. Normality of the continuous variables was examined using Kolmogrov Smimov test. The Wilcoxon- signed rank test was performed for comparison of gait ability and static balance by condition. The alpha level was set at 0.05 for all analyses.

\section{Results}

This study investigated the effect of the elastic band orthosis on balance as compared with bare foot condition. TUG and BBS showed significant improvement with use of the elastic band orthosis (Table 2).

No significant difference was observed in the affected and less-affected single limb support when participants walked with or without the elastic band orthosis. However, use of the elastic band orthosis resulted in significantly improved velocity and cadence in stroke patients $(p<0.05)$. In addition, a significant difference in step length of the less-affected limb was observed between the two conditions ( $p$ $<0.05$ ); however, no significant difference was observed on the affected side (Table 3). When the patients walked using

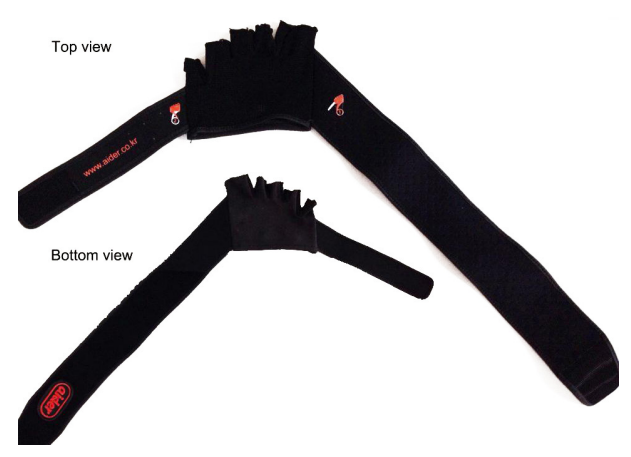

Figure 2. The elastic band orthosis.

Table 2. Comparison of balance with and without the elastic band orthosis in stroke patients

\begin{tabular}{lllcl}
\hline & \multicolumn{2}{c}{ Barefoot } & With the elastic band orthosis & $p^{\text {a }}$ \\
\hline \multirow{2}{*}{ TUG (sec) } & Mean (SD) & $23.2(15.2)$ & $20.0(13.1)$ & 0.005 \\
\multirow{2}{*}{ BBS (score) } & Median (min, max) & $17.0(10,60)$ & $15.0(9,52)$ & 0.013 \\
& Mean (SD) & $42.7(7.1)$ & $45.3(6.4)$ & $45.5(30,53)$ \\
\hline
\end{tabular}

${ }^{a}$ Wilcoxon-signed rank test.

TUG: Timed Up and Go test, BBS: Berg Balance Scale. 
Table 3. Comparison of gait parameters with and without the elastic band orthosis in stroke patients $(\mathrm{N}=10)$

\begin{tabular}{|c|c|c|c|}
\hline & Barefoot & With the elastic band orthosis & $p^{\mathrm{a}}$ \\
\hline Cadence (steps/min) & $81.07(20.73)$ & $85.61(24.35)$ & 0.047 \\
\hline Mean (min, $\max )$ & $77.08(55.33,106.36)$ & $83.64(58.1,121.4)$ & \\
\hline Velocity $(\mathrm{m} / \mathrm{sec})$ & $0.58(0.20)$ & $0.53(0.22)$ & 0.035 \\
\hline Mean (min, max) & $0.47(0.30,0.86)$ & $0.49(0.28,0.89)$ & \\
\hline Less-affected step length $(\mathrm{cm})$ & $35.98(9.23)$ & $37.89(8.25)$ & 0.005 \\
\hline Mean (min, $\max )$ & $33.18(24.56,52.33)$ & $35.41(28.4,52.7)$ & \\
\hline Affected step length $(\mathrm{cm})$ & $36.54(8.36)$ & $36.61(8.48)$ & 0.877 \\
\hline Mean (min, $\max )$ & $35(27,52)$ & $35(26,51.7)$ & \\
\hline Less-affected stride length $(\mathrm{cm})$ & $70.72(15.06)$ & $75.43(13.00)$ & 0.011 \\
\hline Mean (min, max) & $70.36(43.83,100.4)$ & $73.53(57.23,99.33)$ & \\
\hline Affected stride length $(\mathrm{cm})$ & $73.47(12.70)$ & $72.88(12.89)$ & 0.444 \\
\hline Mean (min, max) & $72.9(56.7,100.2)$ & $73.2(54.5,98)$ & \\
\hline Less-affected Single limb support (\%) & $25.28(7.41)$ & $23.29(6.19)$ & 0.005 \\
\hline Mean (min, max) & $27.1(10.4,33.7)$ & $24.55(11.5,32.5)$ & \\
\hline Affected Single limb support (\%) & $25.23(8.41)$ & $36.01(10.42)$ & 0.059 \\
\hline Mean (min, $\max )$ & $26.85(9.83,36.83)$ & $32.8(25.5,60.56)$ & \\
\hline
\end{tabular}

Values are presented as mean (SD).

${ }^{\mathrm{a}}$ Wilcoxon-signed rank test.

the elastic band orthosis, affected and less-affected stride length were also significantly increased as compared with barefoot gait ( $p<0.05$; Table 3 ). For the single limb support, there was a significant difference between the two condition in the less-affected limb $(p<0.05)$, but not in the affected limb.

\section{Discussion}

This study investigated the effect of the elastic band orthosis on balance and gait ability as compared with bare foot condition. We performed measurements using the TUG test, BBS, and walking on the opto-gait system for testing balance and gait parameters. Significant differences were observed in TUG, BBS, velocity, cadence, step length, stride length, and single limb support. However, the single limb support ratio showed no significant difference. Under elastic band orthosis conditions, stability in balance showed significant improvement, with faster walking and longer stride length, compared with the bare foot condition. Many studies investigated the effects of AFOs on balance or walking ability. Significant improvement in velocity, step length, or increased dorsiflexion degrees during walking has been reported, however, no significant differences were observed in stance phase and cadence [19-21]. These results are similar to velocity and stance phase of the current study.

Architecture of the elastic band orthosis consists of heel opened toe socks and two straps. Sock length is toe to mid- metatarsal area and the heel is opened. Straps are attached on both sides of the socks. The long strap, which is attached on the medial side, goes over the top of the lateral malleolus and is turned around to the opposite side and then fastened with Velcro and that may pull up the foot so that it can assist in dorsiflexion. The short strap, which is attached on the lateral side of the socks, goes across top of the foot and is fastened with Velcro, which may assist with eversion. This aid may help in prevention of spastic foot drop, leading to improvement of walking ability. Heel contact (heel strike, heel off) plays an important role during walking. Through heel contact to obtain proprioception, pressure and leg recruit pattern information can be obtained [22]. This movement can act as a switch of the stance phase. Therefore, open-heeled elastic band orthosis can provide greater communication of body scheme information to the central nervous system. In addition, a recent study reported that open-heeled AFO decreased external rotation of the foot. Elastic band orthosis made of fabric is lighter, cheaper, and convenient for wearing shoes compared with conventional plastic AFOs. Light weight of the orthosis is useful for weakened muscles of the legs in stroke patients.

Previous studies indicated that, AFO improves balance ability, which was identified by BBS and fall risk test $[23,24]$. In order for the arm to reach forward, ankle strategy and hip strategy are needed. Liao and Lin [25] reported higher correlation between reach distance and center of mass displacement with ankle strategy, and reaching a greater dis- 
tance was highly related to trunk and hip flexion. In addition, trunk and hip flexion was highly related to ankle plantarflexion. This finding indicates that with AFO application, ankle dorsiflexion is fixed, limiting forward reach.

The material of the elastic band orthosis seems to be more flexible than that of the plastic AFO, indicating less limitation of dorsiflexion compared with that of the plastic AFO.

This study had several limitations. The main limitation of this study was the small number of subjects. Therefore, the results may not be generalized to all stroke patients. Because this was a cross-sectional study, we could not determine a long term effect. In addition, we could not determine which effect is better because no comparison of the conventional AFO and elastic band orthosis had been conducted. In addition, changes in gait distance of the affected side was not significant.

In this study, we compared balance and gait ability with and without the elastic band orthosis in stroke patients. Patients walking with the elastic band orthosis showed increased TUG, BBS, velocity, cadence, step length, stride lengths and single limb support when compared to walking without the elastic band orthosis. Based on three findings, wearing the elastic band orthosis was shown to be better than the barefoot condition. The elastic band orthosis may be used in the clinic as an assistive walking device that is lighter and less expensive for gait training in stroke patients. In addition, gait training should be adapted over a long period of time with the elastic band orthosis in order to assess its effects on stroke patients.

\section{References}

1. Davies P. Steps to follow: the comprehensive treatment of patients with hemiplegia. Springer Verlag; 2003.

2. Platts MM, Rafferty D, Paul L. Metabolic cost of over ground gait in younger stroke patients and healthy controls. Med Sci Sports Exerc 2006;38:1041-6.

3. Detrembleur C, Dierick F, Stoquart G, Chantraine F, Lejeune T. Energy cost, mechanical work, and efficiency of hemiparetic walking. Gait Posture 2003;18:47-55.

4. Lamontagne A, Stephenson JL, Fung J. Physiological evaluation of gait disturbances post stroke. Clin Neurophysiol 2007;118: 717-29.

5. Shumway-Cook A, Woollacott MH. Motor control: translating research into clinical practice. 3rd ed. Philadelphia: Lippincott Williams \& Wilkins; 2007.

6. Condie E, Campbell J, Martina J; International Society for Prosthetics and Orthotics. Report of a consensus conference on the orthotic management of stroke patients: held at Avegoor Conference Centre, Ellecom, Netherlands, 21st-26th September
2003. Copenhagen: International Society for Prosthetics and Orthotics; 2004.

7. Dietz V, Quintern J, Berger W. Electrophysiological studies of gait in spasticity and rigidity. Evidence that altered mechanical properties of muscle contribute to hypertonia. Brain 1981;104: 431-49.

8. Burridge JH, Taylor PN, Hagan SA, Wood DE, Swain ID. The effects of common peroneal stimulation on the effort and speed of walking: a randomized controlled trial with chronic hemiplegic patients. Clin Rehabil 1997;11:201-10.

9. Practice analysis of certified practitioners in the disciplines of orthotics and prosthetics [database on the Internet]. 2007 [cited October 16, 2008]. Available from: http://www.abcop.org/ Practice_Analysis.asp.

10. Jutai J, Coulson S, Teasell R, Bayley M, Garland J, Mayo N, et al. Mobility assistive device utilization in a prospective study of patients with first-ever stroke. Arch Phys Med Rehabil 2007;88: 1268-75.

11. Lehmann JF, Condon SM, Price R, deLateur BJ. Gait abnormalities in hemiplegia: their correction by ankle-foot orthoses. Arch Phys Med Rehabil 1987;68:763-71.

12. Tyson SF, Thornton HA. The effect of a hinged ankle foot orthosis on hemiplegic gait: objective measures and users' opinions. Clin Rehabil 2001;15:53-8.

13. Geboers JF, Drost MR, Spaans F, Kuipers H, Seelen HA. Immediate and long-term effects of ankle-foot orthosis on muscle activity during walking: a randomized study of patients with unilateral foot drop. Arch Phys Med Rehabil 2002;83:240-5.

14. Podsiadlo D, Richardson S. The timed "Up \& Go": a test of basic functional mobility for frail elderly persons. J Am Geriatr Soc 1991;39:142-8.

15. Ng SS, Hui-Chan CW. The timed up \& go test: its reliability and association with lower-limb impairments and locomotor capacities in people with chronic stroke. Arch Phys Med Rehabil 2005;86:1641-7.

16. Berg KO, Wood-Dauphinee SL, Williams JI, Maki B. Measuring balance in the elderly: validation of an instrument. Can J Public Health 1992;83(Suppl 2):S7-11.

17. Mao HF, Hsueh IP, Tang PF, Sheu CF, Hsieh CL. Analysis and comparison of the psychometric properties of three balance measures for stroke patients. Stroke 2002;33:1022-7.

18. Lienhard K, Schneider D, Maffiuletti NA. Validity of the Optogait photoelectric system for the assessment of spatiotemporal gait parameters. Med Eng Phys 2013;35:500-4.

19. Gök H, Küçükdeveci A, Altinkaynak H, Yavuzer G, Ergin S. Effects of ankle-foot orthoses on hemiparetic gait. Clin Rehabil 2003;17:137-9.

20. Cakar E, Durmus O, Tekin L, Dincer U, Kiralp MZ. The ankle-foot orthosis improves balance and reduces fall risk of chronic spastic hemiparetic patients. Eur J Phys Rehabil Med 2010; 46:363-8.

21. Hwang YI, Yoo WG, An DH. Effects of the Elastic Walking Band on gait in stroke patients. NeuroRehabilitation 2013;32: 317-22.

22. Kim HJ, Chun MH, Kim HM, Kim BR. Effects on foot external rotation of the modified ankle-foot orthosis on post-stroke hemiparetic gait. Ann Rehabil Med 2013;37:516-22.

23. Simons CD, van Asseldonk EH, van der Kooij H, Geurts AC, 
Buurke JH. Ankle-foot orthoses in stroke: effects on functional balance, weight-bearing asymmetry and the contribution of each lower limb to balance control. Clin Biomech (Bristol, Avon) 2009;24:769-75.

24. Doğan A, Mengüllüoğlu M, Özgirgin N. Evaluation of the effect of ankle-foot orthosis use on balance and mobility in hemiparetic stroke patients. Disabil Rehabil 2011;33:1433-9.

25. Liao CF, Lin SI. Effects of different movement strategies on forward reach distance. Gait Posture 2008;28:16-23. 